\title{
Species-specific responses of growth and biomass distribution to trellis availability in three temperate lianas
}

\author{
Tomasz P. Wyka ${ }^{1}$ (1) $\cdot$ Marcin Zadworny ${ }^{2} \cdot$ Joanna Mucha ${ }^{2} \cdot$ Roma Żytkowiak $^{2} \cdot$ Kinga Nowak $^{2} \cdot$ Jacek Oleksyn $^{2,3}$
}

Received: 8 November 2018 / Accepted: 19 February 2019 / Published online: 27 February 2019

(c) The Author(s) 2019

\begin{abstract}
Key message In some lianas the use of trellis modifies within-plant biomass allocation and stimulates growth, however in other species trellis use may negatively affect growth indicating a cost associated with climbing.

Abstract In order to improve access to light, lianas use other plants as climbing trellises. Whereas in shaded lianas climbing a trellis may enhance biomass gain by increasing leaf-level irradiance, we suspected that trellis use may also stimulate growth by triggering modifications in whole-plant allocation of biomass and nitrogen. We evaluated responses to trellis in three temperate lianas: Hedera helix, Celastrus orbiculatus and Wisteria floribunda. Lianas were grown outdoors in 120-L barrels and with ample space, with and without trellises. Biomass and nitrogen accumulation, distribution patterns and total stem length were determined after three and four seasons. Responses were adjusted for individual plant biomass. Liana responses to trellises were species-specific. In W. floribunda trellis use enhanced growth, consistently with the increased leaf mass fraction and leaf area ratio while biomass distribution to roots was reduced. Biomass distribution to stems and total stem length were increased by trellis use. In contrast, growth and biomass distribution in C. orbiculatus were not altered by trellis use. In H. helix growth was reduced in plants climbing on trellises in comparison with plants creeping on the ground, but biomass distribution pattern was not altered. Moreover, supported $H$. helix plants accumulated less nitrogen than did unsupported plants, suggesting a less efficient uptake of this nutrient. The ability to plastically modify growth and allocation patterns in response to trellis found in some lianas may constitute an important aspect of their ecological strategy. In other species, however, the switch to climbing may incur physiological costs resulting in lower growth.
\end{abstract}

Keywords Biomass allocation $\cdot$ Climbers $\cdot$ Biomass partitioning $\cdot$ Growth form $\cdot$ Plasticity $\cdot$ Vines

Communicated by van der Maaten.

Electronic supplementary material The online version of this article (https://doi.org/10.1007/s00468-019-01828-3) contains supplementary material, which is available to authorized users.

Tomasz P. Wyka

twyka@amu.edu.pl

1 General Botany Laboratory, Institute of Experimental Biology, Faculty of Biology, Adam Mickiewicz University, Umultowska 89, 61-614 Poznan, Poland

2 Institute of Dendrology, Polish Academy of Sciences, Parkowa 5, 62-035 Kórnik, Poland

3 Department of Forest Resources, University of Minnesota, St. Paul, MN 55108, USA

\section{Introduction}

Lianas are a morphologically and phylogenetically diverse group of woody plants producing relatively flexible stems that use the support of other plants in order to place their own foliage under favorable irradiance (Darwin 1865; Gentry 1991). External support allows liana shoots to reach the forest canopy (Putz 1984; Valladares et al. 2011), minimize leaf self-shading (Ackerly 1992) and escape from herbivores (Gianoli and Molina-Montenegro 2005). In many lianas, reproduction is initiated only after reaching the canopy (Putz 1984). The presence of suitable trellis is thus a vital characteristic of the lianas' environment, permitting full expression of their growth potential and completion of the life cycle.

Lianas actively search for support by employing a variety of searching movements or directional tropic growth (Strong and Ray 1975; Larson 2000; Isnard and Silk 2009). In natural environment, proximity of suitable trellises is, however, 
not always granted (Putz 1984). A liana that fails to locate a trellis in its immediate surroundings may die (Nabe-Nielsen 2004), form prostrate searching shoots (Sakai et al. 2002) or form a self-supporting, free-standing "waiting" form (Gartner 1991a; Gallenmüller et al. 2004). In many liana species self-supporting forms constitute a regular, juvenile phase of the life cycle, which sometimes persists for many years (Putz 1984; Angyalossy et al. 2012). The control of the switch between self-supporting and climbing phase is largely unknown, but the transition may be induced by increased availability of light signaling a gap opening (Rowe and Speck 2005) or, seemingly, by the very proximity of support (Gartner 1991a). This change may be accompanied by a transformation of external stem structure and internal anatomy (Gartner 1991c; Angyalossy et al. 2012). The majority of lianas, however, do not produce distinct alternative growth forms but rather respond to absence/availability of trellis with plastic, quantitative adjustment of morphology.

In various climbing plants the recurring response triggered by support has been the increase in length of the leader shoot (Putz 1984; den Dubbelden and Oosterbeek 1995; Sakai and Suzuki 1999; Gianoli 2002), sometimes accompanied by reduction in branching (den Dubbelden and Oosterbeek 1995). These and other morphological adjustments of lianas in response to trellis availability may potentially result in modified patterns of biomass distribution among specific organ fractions. For example, stimulation of stem extension by trellis, especially if effected through an increased internode length, may be expected to increase biomass allocation to stems. With the additional space for leaf display, allocation of biomass to leaves may also be favored. Further, the need for root anchorage may be lower in plants using support than in plants producing free-standing or creeping forms, while, on the other hand, creeping shoots may produce extensive adventitious roots. A climbing liana may thus allocate more biomass (and other resources, such as nitrogen) to aboveground parts than an unsupported liana. Moreover, the evolutionary advantages of the lianescent habit are thought to have involved an increased resource allocation to photosynthetically productive foliage accompanied by reduced costs of accessory organs (stems or roots, Darwin 1865; Wyka et al. 2013). To the extent that expression of such habit-specific allocation pattern depends on the use of external support, trellis-using lianas may be hypothesized to show higher leaf biomass fractions than unsupported lianas, when exposed to otherwise similar conditions (as shown for vertical vs. horizontal shoots of Hedera helix; Frey and Frick 1987).

Actual reports on biomass distribution in supported vs. unsupported climbers are scarce and contradictory. Den Dubbelden and Oosterbeek (1995) showed that supported herbaceous climbers decrease distribution of biomass to searching shoots and increase distribution to roots. In contrast, in unsupported liana W. floribunda biomass distribution to roots increased, and distribution to stems decreased while distribution to leaves remained unaffected relative to supported plants (Sakai and Suzuki 1999). Moreover, since gradual accumulation of structural biomass with time affects the ratio between mass of leaves and the more permanent supporting organs (stems and main roots; Poorter and Sack 2012), plant biomass distribution ratios often scale with plant size (Poorter et al. 2015). Controlling for plant size is thus potentially critical in biomass distribution studies. Interpretation of biomass distribution patterns in the above trellis-availability studies is complicated by the lack of plant size control when supported and unsupported plants differed in biomass at harvest (e.g., nearly twofold difference in the study by Sakai and Suzuki 1999). More, the published reports on trellis effect on whole-plant biomass distribution cover only small plants (up to $250 \mathrm{~g}$ dry mass in Sakai and Suzuki 1999) or only consider aboveground parts (Gartner 1991b; Tsugawa et al. 1992; Gianoli 2002). Reports of whole-plant studies performed on large liana individuals are, to our knowledge, not available.

Although trellis may be considered a vital resource, especially in lianas requiring escape from shade into tree canopy (Ackerly 1992), the effect of trellis use per se on plant biomass accumulation rate has not been well documented. Trellis availability has been shown to encourage whole plant growth in liana Wisteria floribunda (Sakai and Suzuki 1999) but not in herbaceous climbers (Tsugawa et al. 1992; den Dubbelden and Oosterbeck 1995), while in herbaceous straggler Galium aparine growth stimulation due to trellis use occurred only at highest plant densities (Puntieri and Pyšek 1993). There was also no significant increase in aboveground biomass accumulation by climbing vs. prostrate plants of Ipomoea purpurea (Gianoli 2002), Pueraria lobata (Tsugawa et al. 1992) or viny vs. shrubby forms of Toxicodendron diversilobum (Gartner 1991b). Since indices of within-plant biomass distribution, especially the ratio of leaf mass and area to whole plant biomass are important correlates of the plant growth rate (Evans 1972), we hypothesized that, in cases when trellis climbing causes an increase in leaf investment, the supported lianas should exhibit a faster growth than unsupported lianas. Empirical determination of both the biomass accumulation rates and the distribution patterns should help to understand the mechanisms by which trellis availability controls liana growth.

Here, we undertook an experimental investigation of the effect of trellis availability on biomass and nitrogen distribution and growth rate in three species of temperate lianas: Hedera helix, Celastrus orbiculatus and Wisteria floribunda. We grew plants in large $(120 \mathrm{~L})$ containers over four growing seasons and performed two sequential harvests to obtain data on whole plant biomass accumulation and distribution for a range of plant sizes. We hypothesized that, at 
comparable biomass, trellis availability will: (1) stimulate stem elongation, (2) increase relative biomass distribution to stems and (3) increase relative allocation of biomass and nitrogen to leaves. We further presumed that such altered allocation patterns will (4) lead to an enhanced whole-plant biomass accumulation.

\section{Materials and methods}

\section{Plant cultivation}

Seeds of three species of temperate lianas: a European root climber Hedera helix (Araliaceae), an East-Asian stem twinner Celastrus orbiculatus (Celastraceae) and a Japanese stem twinner Wisteria floribunda (Fabaceae) were obtained commercially ( $W$. floribunda) or collected from several cultivated (C. orbiculatus) or naturally occurring (H. helix) individuals. Species selection was dictated by their diverse forms and reliable hardiness under the local conditions. Seeds were germinated in laboratory in spring 2013 and seedlings were planted in 3-L pots filled with peatbased potting compost with the addition of $20 \%$ perlite and gradually acclimated to outdoor conditions. C. orbiculatus and $W$. floribunda were planted in outdoor experimental garden at Polish Academy of Sciences Institute of Dendrology $\left(55^{\circ} 14^{\prime} 38^{\prime \prime} \mathrm{N}\right.$ and $\left.17^{\circ} 6^{\prime} 6^{\prime \prime} \mathrm{E}\right)$ in late June, and H. helix in mid-August, 2013.

Plant cultivation was carried out in $120 \mathrm{~L}$ barrels fitted with bottom drainage and filled with pre-sifted top soil from a local forest site enriched with $3 \mathrm{~g} \mathrm{~L}^{-1}$ slow release fertilizer (Osmocote 16-9-12-2 N-P-K-Mg, with trace nutrients). The barrels were arranged in three parallel blocks, consisting of two rows and aligned along the EW direction. The distance between barrels in each row and between the rows was $0.5 \mathrm{~m}$, and the blocks were set $2 \mathrm{~m}$ apart. Ground between barrels was lined with black cloth to suppress weeds. Harvesting selected plants for this and an accompanying study (manuscript in preparation) in consecutive years permitted to gradually increase spacing between plants. Each species was grown in a different block. The entire block containing $H$. helix (a shade demanding species) was additionally protected by a $3 \mathrm{~m}$ tall shade house covered with net transmitting $70 \%$ of solar irradiance. Plants were regularly watered to field capacity using a drip irrigation system. Since the rationale of the experiment was to evaluate the effect of trellis as the sole growth-limiting resource, $160 \mathrm{~g}$ of Osmocote fertilizer (a dose calculated on the basis of recommendation for container nurseries) was applied to each barrel at the beginning of each growing season. Chemical pest and disease control was applied as needed.

Plants were assigned to either supported or unsupported category. Unsupported plants received no stakes and were allowed to grow outside the barrel without restriction. In case of incidental contact with neighboring plants, stems were gently untwined but were allowed to twine around other stems of the same plant. In the supported group, each plant was supplied with a trellis. For the twinning species C. orbiculatus and W. floribunda two 2.5-m-long wooden stakes (50 $\mathrm{mm}$ diameter and round in cross-section) were placed immediately next to each barrel in the beginning of the 2014 season. In the following season two more such stakes were provided and an additional pair of 5-m-long stakes, $80 \times 80 \mathrm{~mm}$ thick and square in cross-section, were also inserted $80 \mathrm{~cm}$ into the ground at $0.5 \mathrm{~m}$ distance from the edge of each barrel resulting in six stakes per plant in the final two seasons of the experiment. For the root climber H. helix two 2.5-m-long stakes lined with coconut fiber mat were provided in 2014 and six additional stakes were added in the following season to each barrel to create a dense palisade of eight stakes. Stakes were always placed around the northern edge of the barrel.

Occasionally plants were eliminated from the experiment as a result of mechanical damage by wind, failure of irrigation or drainage, or visible stress caused by unknown factors. This elimination resulted in unequal sample sizes among species, typically amounting to 5 plants per species per harvest (range 4-8, Fig. 1A).

\section{Harvest and biomass processing}

Plants were harvested at the culmination of 2015 and 2016 growing seasons, but before the beginning of autumnal leaf senescence. Each year the harvesting campaign started in late August and was completed by mid-September. Plants of one species were harvested within the same week to reduce intraspecific variability. Aboveground parts were cut off at soil level and separated into stems and leaves, and, where present, flowers and fruits. Total length of all stems per plant was measured with a measuring tape. Adventitious roots that formed on creeping H. helix and (rarely) W. floribunda stems outside of the barrels, were carefully excavated from soil using hand shovel and eventually included in the general root biomass. Barrels containing root systems were lifted, cut open and entire root systems were recovered by washing off soil using water hose followed by thorough rinsing in a basin. Roots were then blotted with paper towels and briefly surface-dried in free air.

All biomass fractions were dried at $65{ }^{\circ} \mathrm{C}$ in forcedventilation ovens for at least $72 \mathrm{~h}$ for determination of dry mass. In 2016 when leaf harvest was very bulky, total fresh leaf mass per plant was determined at harvest and two subsamples of about $250 \mathrm{~g}$ fresh mass were taken for dry mass determination. Total dry leaf biomass was then determined from dry mass to fresh mass ratio. Leaf, stem and root mass fractions (respectively LMF, SMF and RMF, \%) 
Fig. 1 Effects of trellis availability on whole plant (A) and aboveground (B) biomass, and the whole plant $\mathrm{N}$ pool $(\mathbf{C})$ in three species of temperate lianas at two annual harvest. Means \pm S.E. are shown. Numbers of plants harvested in a given year are indicated above each bar in A. Results of two-way analysis of variance with trellis availability and harvest year as main effects are presented separately for each species. Asterisks indicate statistical significance of Anova effects: $* P<0.05, * * P<0.01$, $* * * P<0.001$, n.s. not significant. Significant pre-planned contrasts between treatments within year are indicated by asterisks placed above pairs of bars

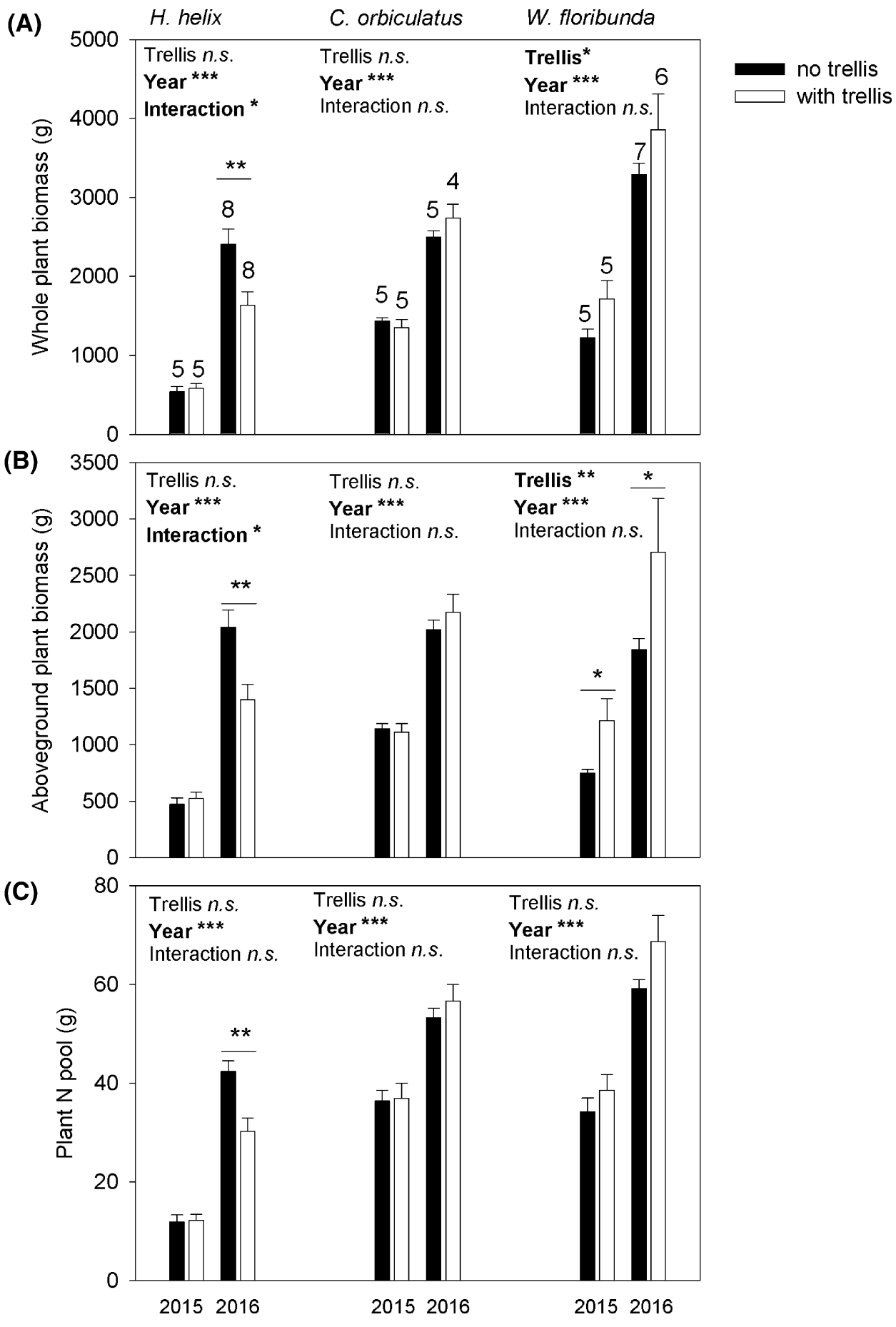

were calculated by dividing the dry mass of each fraction by the whole plant dry mass. Adventitious root mass fraction (ARMF, \%) was determined by dividing adventitious root mass by total root mass. Specific stem length (SSL, $\mathrm{cm} \mathrm{g}^{-1}$ ) was calculated as the ratio of total stem length to total stem mass per plant.

\section{Laboratory analyses}

Ten leaves were randomly picked from each plant for determination of leaf mass per area (LMA). Petioles (or segments of rachises below the lowermost leaflet in case of compound Wisteria leaves) were separated and laminas 
were individually scanned with a desktop scanner. Leaf parts were dried at $65{ }^{\circ} \mathrm{C}$ for $72 \mathrm{~h}$ and weighed, and mean plant lamina mass to whole leaf mass ratio (LamR, $\mathrm{g} \mathrm{g}^{-1}$ ) was estimated. LMA was determined as the ratio of lamina dry mass to its area $\left(\mathrm{g} \mathrm{m}^{-2}\right.$ ). Leaf area ratio (LAR, $\mathrm{cm}^{2} \mathrm{~g}^{-1}$ ) was calculated for each plant according to the formula: $\mathrm{LAR}=\mathrm{LamR} \times \mathrm{LMF} \times \mathrm{LMA}^{-1}$.

Entire batches of dry stems and roots were cut into 2-3 cm chips. Each biomass fraction was then thoroughly mixed to ensure representative sampling of the tissue. A handful of tissue was ground to $1 \mathrm{~mm}$ grade powder in a laboratory mill (IKE Labortechnik, Germany) followed by fine grinding in a ball mill (IKE Labortechnik, Germany). Nitrogen concentration was determined using an Elemental Combustion System CHNS-O 4010 (Costech Instruments, Italy/USA). Whole plant $\mathrm{N}$ content was determined by multiplying $\mathrm{N}$ concentration of each fraction by the biomass of that fraction and adding up these organ-specific $\mathrm{N}$ pools. Leaf nitrogen fraction (LNF) was determined as ratio of leaf $\mathrm{N}$ pool to whole plant $\mathrm{N}$ pool.

\section{Statistics}

Statistical analyses were conducted separately for each species. The two-way analysis of variance was used to evaluate the effect of trellis availability and harvest year on whole plant and aboveground biomass, N pool, SSL, LMA and leaf $\mathrm{N}$ concentration, followed by analysis of pre-planned contrasts between groups. To evaluate the effect of trellis availability on biomass or $\mathrm{N}$ distribution ratios, analysis of covariance was used, with whole plant biomass (or, respectively, plant $\mathrm{N}$ pool) as the continuous covariate. Where the support $\times$ covariate interaction was not significant, it was excluded from the model and analyses were re-run. Biomass and $\mathrm{N}$ pool were log-transformed for all analyses.

\section{Results}

All plants supplied with trellises used them for support although sporadic shoots in C. orbiculatus and W. floribunda, and a significant number of shoots in. H. helix failed to locate or accept support and grew horizontally. In. H. helix some shoots after initial growth on support descended to the ground. The effect of trellis availability on liana biomass was species-specific (Fig. 1A). In H. helix, mean whole-plant biomass accumulation was lower in supported comparing to unsupported plants although the difference occurred only at final harvest. Growth of W. floribunda was stimulated by trellis climbing $(P=0.04)$ although contrasts at specific harvests were not significant $(2015 P=0.055 ; 2016 P=0.320)$, whereas $C$. orbiculatus reached the same biomass in both climbing and non-climbing group. Accordingly, the largest
$H$. helix plant was an unsupported individual that reached $3.3 \mathrm{~kg}$ d.m., whereas the largest $C$. orbiculatus and $W$. floribunda grew on trellis and reached, respectively, 2.9 and $6.0 \mathrm{~kg}$ (Fig. 2). Similar pattern of responses to trellis was found for the aboveground biomass, however within-year contrasts in W. floribunda were stronger than for whole-plant biomass (Fig. 1B vs. A). The lower biomass accumulation in supported H. helix in 2016 resulted in marginally lower plant $\mathrm{N}$ pool in comparison to unsupported plants (support $\times$ year $P=0.058,2016$ contrast $P=0.008$ ), whereas growth stimulation by trellis in $W$. floribunda did not lead to a significant increase of plant $\mathrm{N}$ pool and there was also no trellis effect in C. orbiculatus (Fig. 1C).

In $H$. helix trellis availability did not alter the distribution of biomass among stems, roots and leaves (Fig. 2A, D, G). In C. orbiculatus there was a decrease in LMF in larger individuals (interaction term $P=0.043$ ) without significant effects of trellis on SMF and RMF (Fig. 2B, E, H). Pronounced effects of trellis availability on biomass distribution occurred in $W$. floribunda, with an increase in SMF and decrease in RMF in largest individuals and a highly significant increase in LMF across plant sizes (Fig. 2C, F, I).

The use of trellis caused no change in leaf display (LAR) or ratio of leaf to stem mass in either H. helix or C. orbiculatus but caused an increase in LAR and leaf to stem mass ratio in W. floribunda (Fig. 3A-F). Similarly, trellis availability caused greater partitioning of $\mathrm{N}$ to leaves in $W$. floribunda but not in the other two species (Fig. 3G-I).

Adventitious roots were produced along prostrate shoots of all H. helix plants, in four out of five unsupported W. floribunda plants in 2015 and in two and one prostrate shoots of climbing W. floribunda in, respectively, 2015 and 2016 (Electronic Supplementary Material Table S1). There was, however, no significant effect of support availability on fraction of adventitious roots in total root mass in either species (see Electronic Supplementary Material, legend to Table S1).

After accounting for plant size, we found no effect of trellis on total length of stems in H. helix and C. orbiculatus but found an increase in stem length in supported $W$. floribunda, especially in larger plants (Fig. 4A-C). Stem structure, as indicated by the SSL index was, however, not affected by trellis availability in any of the lianas (Fig. 4D). Support had also no overall influence on leaf structure as measured by LMA in any species, except for a significant support $\times$ year interaction in $H$. helix; however annual contrasts in this species were not significant $(P=0.203$ in 2015 and $P=0.052$ in 2016 with slightly higher LMA in, respectively, supported and unsupported plants; Fig. 5A). Likewise, there were no trellis effects on foliar $\mathrm{N}$ concentration (Fig. 5B).

Whereas $H$. helix and $W$. floribunda showed no reproductive development, some of the $C$. orbiculatus plants bore flowers and/or fruits at times of harvest. Mean reproductive 
H. helix
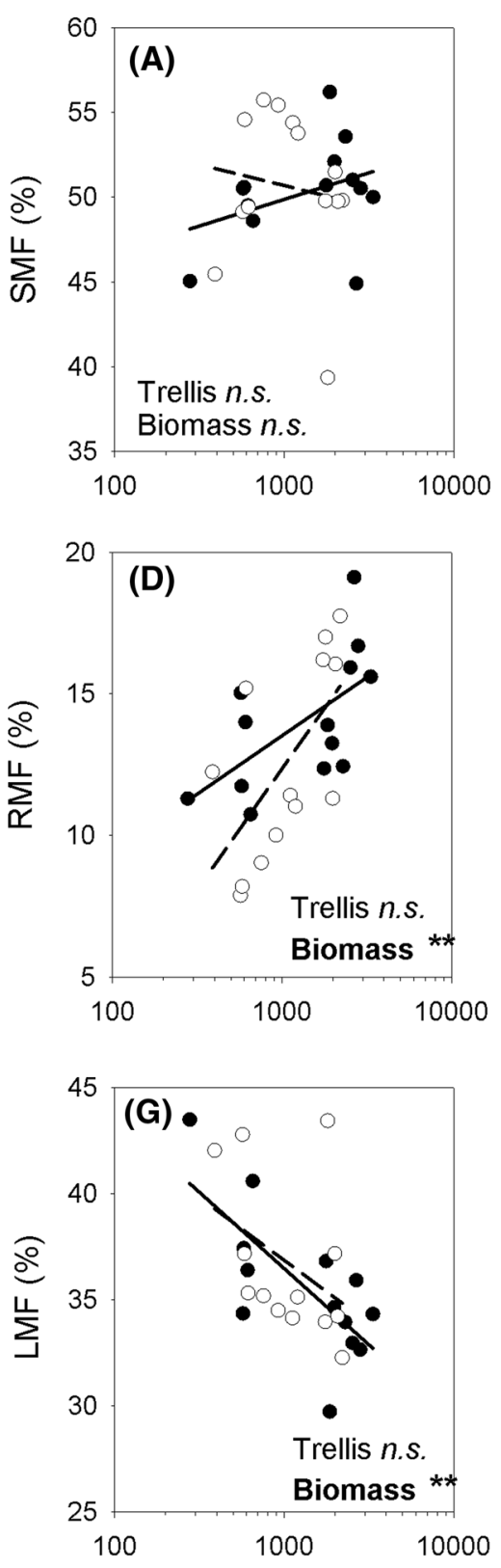

Plant biomass $(\mathrm{g})$
C. orbiculatus
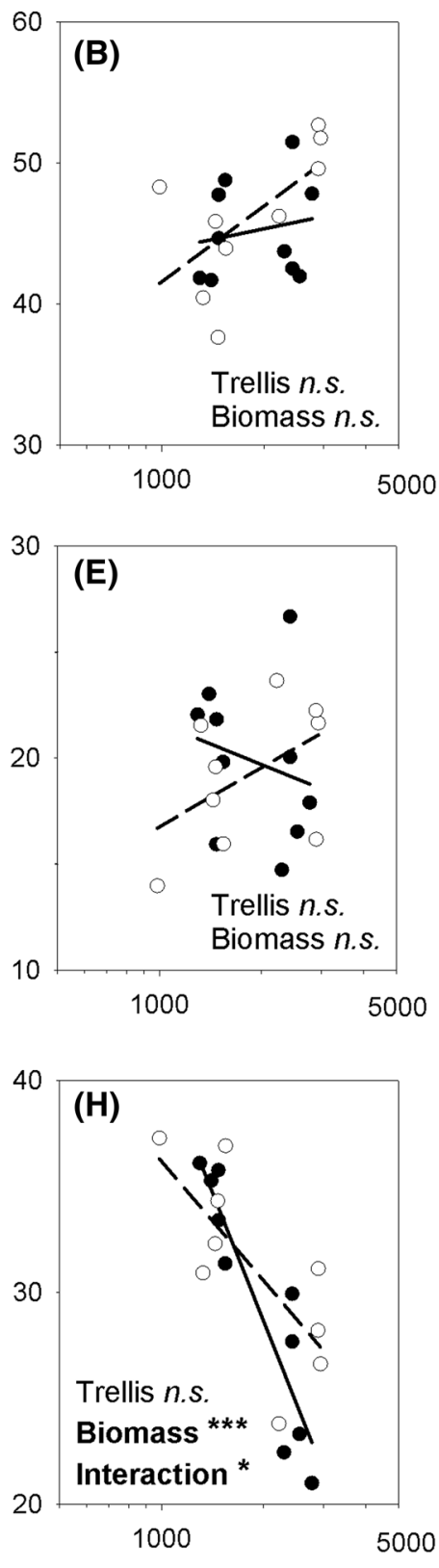

Plant biomass $(\mathrm{g})$
W. floribunda
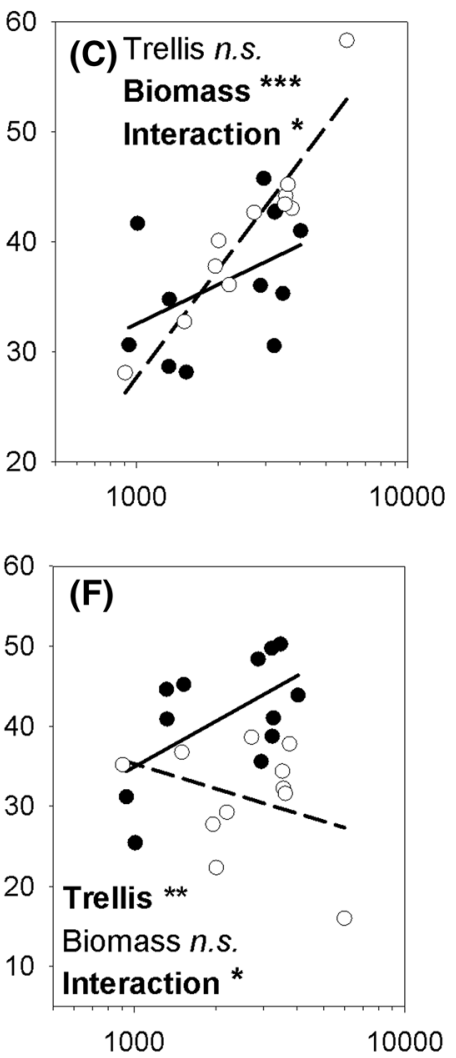

Fig. 2 Effects of trellis availability on biomass distribution to stems (stem mass fraction, SMF; A-C), roots (root mass fraction, RMF; D-F) and leaves (leaf mass fraction, LMF; G-I) in relation to whole plant biomass in three species of temperate lianas. Symbols are data for individual plants. Regression lines are shown (clear symbols and dashed lines-plants with trellises, filled symbols and solid lines- plants with no trellises). Results of analysis of covariance are given, with trellis availability as main effect and biomass as a covariate. Interaction term was omitted from the models when found to be non-significant. Asterisks indicate statistical significance of effects: $* P<0.05, * * P<0.01, * * * P<0.001$, n.s. not significant

including reproductive biomass in total plant mass influenced the effect of trellis availability, we re-run analyses for C. orbiculatus presented in Figs. 1, 2, 3 and 4B using only vegetative biomass and N pool (see Electronic Supplementary Material Figs. S1, S2 and S3). We found that the only 

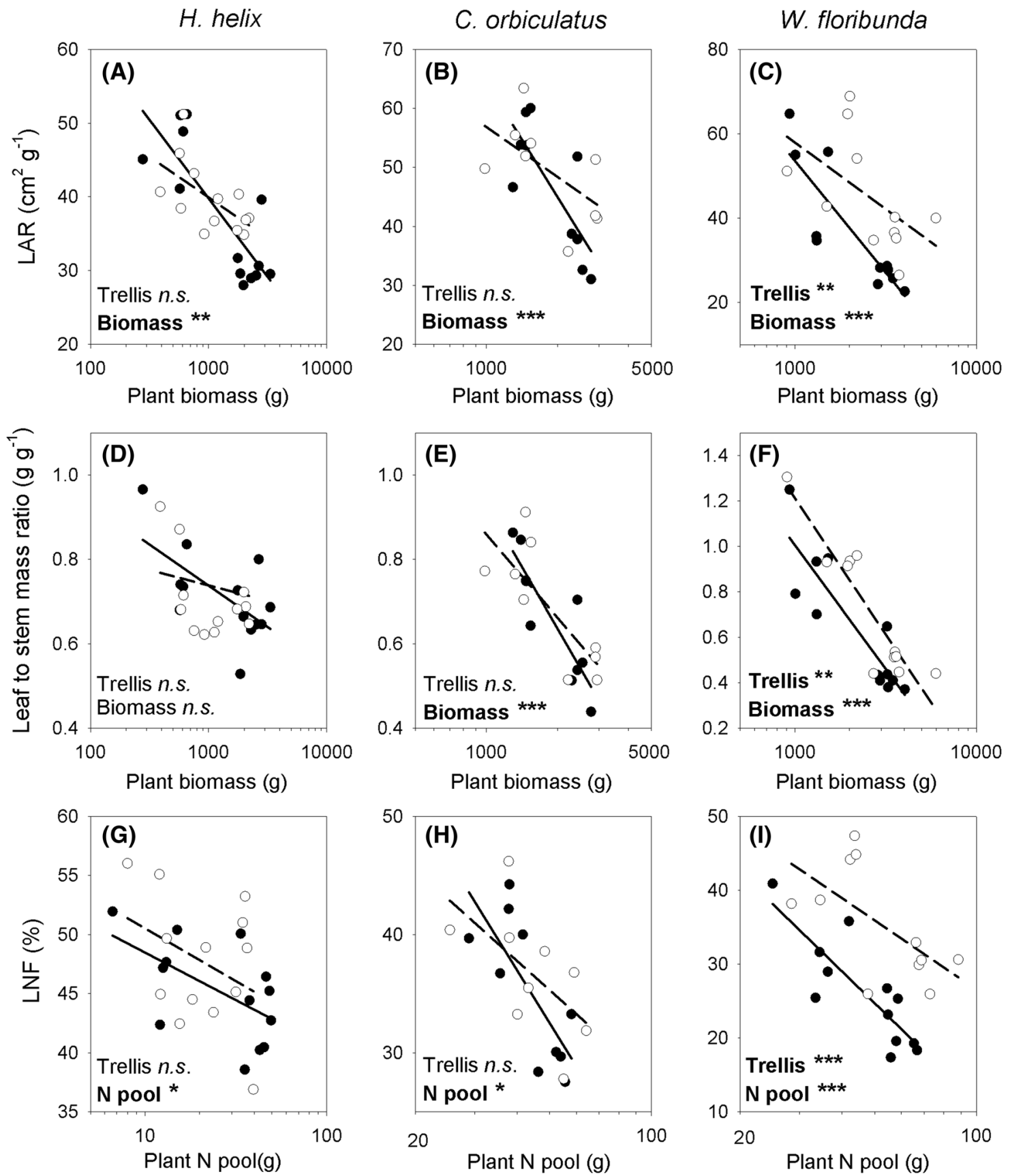

Fig. 3 Effects of trellis availability on leaf display (leaf area index, LAR; A-C), ratio of leaf to stem biomass (D-F) and investment of nitrogen in leaves (leaf nitrogen fraction, LNF; G-I) in relation to whole-plant biomass (A-F) or plant N pool $(\mathbf{G}-\mathbf{I})$ in three species of lianas. Symbols are data for individual plants and regression lines are shown (clear symbols and dashed lines-plants with trellises, filled

effect of removing reproductive biomass was the disappearance of the significant effect of interaction between biomass and trellis availability on LMF (Fig. $2 \mathrm{H}$ vs. Fig. S1). Thus, LMF in $C$. orbiculatus was not affected by trellis availability when only vegetative biomass was considered. symbols and solid lines-plants with no trellises). Results of analysis of covariance are given, with trellis availability as main effect and biomass as a covariate. Interaction term was omitted from the models since they were non-significant in all cases. Asterisks indicate statistical significance of effects: $* P<0.05, * * P<0.01$, $* * * P<0.001, n$.s. not significant

\section{Discussion}

Availability of trellis may be critical for completion of the liana life cycle: achieving sexual reproduction and diaspore dispersion. Climbing may also enable lianas to place leaves 


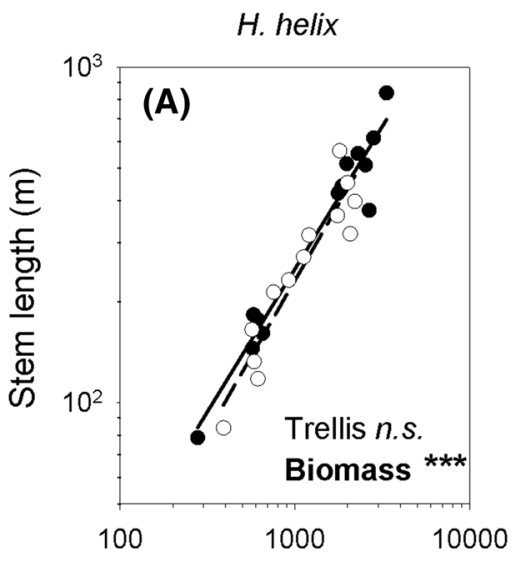

Plant biomass $(\mathrm{g})$
C. orbiculatus

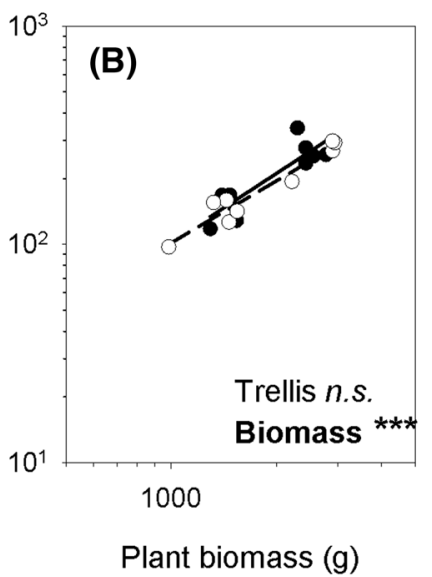

W. floribunda

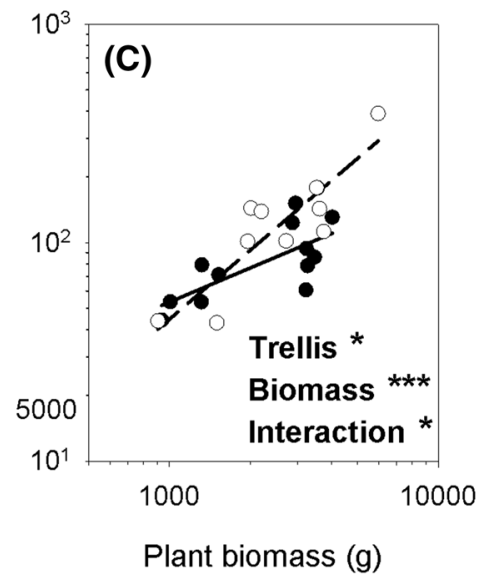

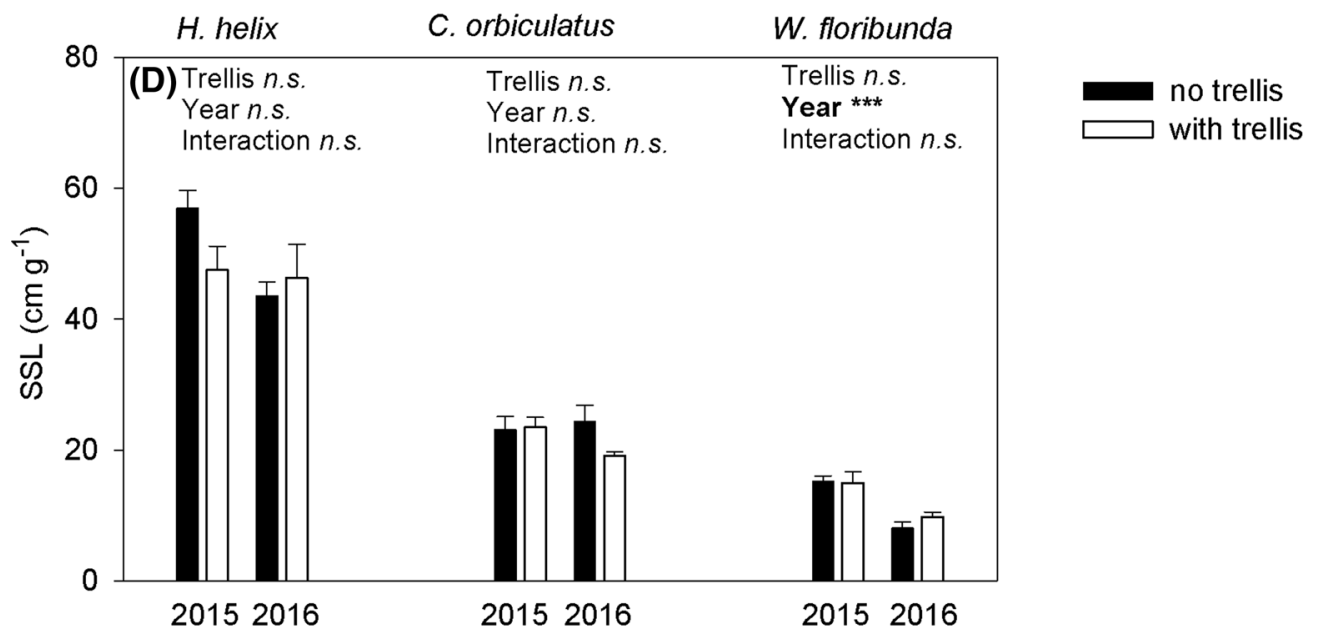

Fig. 4 Effects of trellis availability on total stem length (A-C) and specific stem length (SSL; D) in three species of lianas. Symbols in A-C are data for individual plants and lines indicate regression (clear symbols and dashed lines-plants with trellises, filled symbols and solid lines-plants with no trellises), whereas bars in $\mathbf{D}$ are means $( \pm$ SE). Panels $(\mathbf{A}-\mathbf{C})$ include results of analysis of covariance, with trellis availability as main effect and biomass as a covariate. Interac-

in higher irradiance than that available on forest floor (Putz 1984; Valladares et al. 2011). Although under natural conditions climbing may be a way to escape shading by the canopy, thus increasing the rate of whole-plant carbon gain, we were interested in finding out whether trellis use may stimulate biomass accumulation independently of facilitation of shade escape. This could be achieved through regulatory effect of trellis on resource allocation and meristem activity or the improvement in leaf display efficiency. Our plants were grown under rather uniform irradiance, minimizing the difference in light access between climbing and non-climbing plants. The homogeneity of light conditions is confirmed by the similarity of LMA between supported and unsupported plants, as LMA is a sensitive index of integrated local irradiance (Poorter et al. 2009). tion term was omitted from the models when found to be non-significant. Panel D shows results of two-way analyses of variance with trellis availability and year as the main effects. Analyses were conducted separately for each species. Asterisks indicate statistical significance of effects: $* P<0.05, * * * P<0.001$, n.s. not significant. None of the contrasts between treatments within species and year was significant in D

Contrary to the expectation, we found a significant stimulation of whole-plant biomass accumulation by trellis use in only one of the three lianas ( $W$. floribunda). This result is in line with earlier reports in which, however, relatively larger increases of whole-plant biomass were reported for supported relative to unsupported W. floribunda (Sakai and Suzuki 1999) and Humulus lupulus (den Dubbelden and Oosterbeck 1995). In these studies plants were by an order of magnitude smaller than plants in the present study. On the other hand, biomass accumulation rate in $C$. orbiculatus did not change in response to trellis availability demonstrating that trellis does not stimulate vegetative growth in this species at least as long as well-lit space for prostrate shoot growth is available. Similar lack of stimulatory effect of trellis on climber biomass has been reported in several species 
Fig. 5 Leaf structure (leaf mass per area, LMA; $\mathbf{A}$ ) and foliar $\mathrm{N}$ concentration $(\mathbf{B})$ in three species of temperate lianas grown with or without trellis, determined at 2015 and 2016 harvests. Means \pm SE are shown. Results of two-way analysis of variance with trellis availability and year as main effects are presented separately for each species. Asterisks indicate statistical significance of Anova effects: $* P<0.05$, $* * P<0.01$, *** $P<0.001$, n.s. not significant. None of the contrasts between treatments within species and year were significant

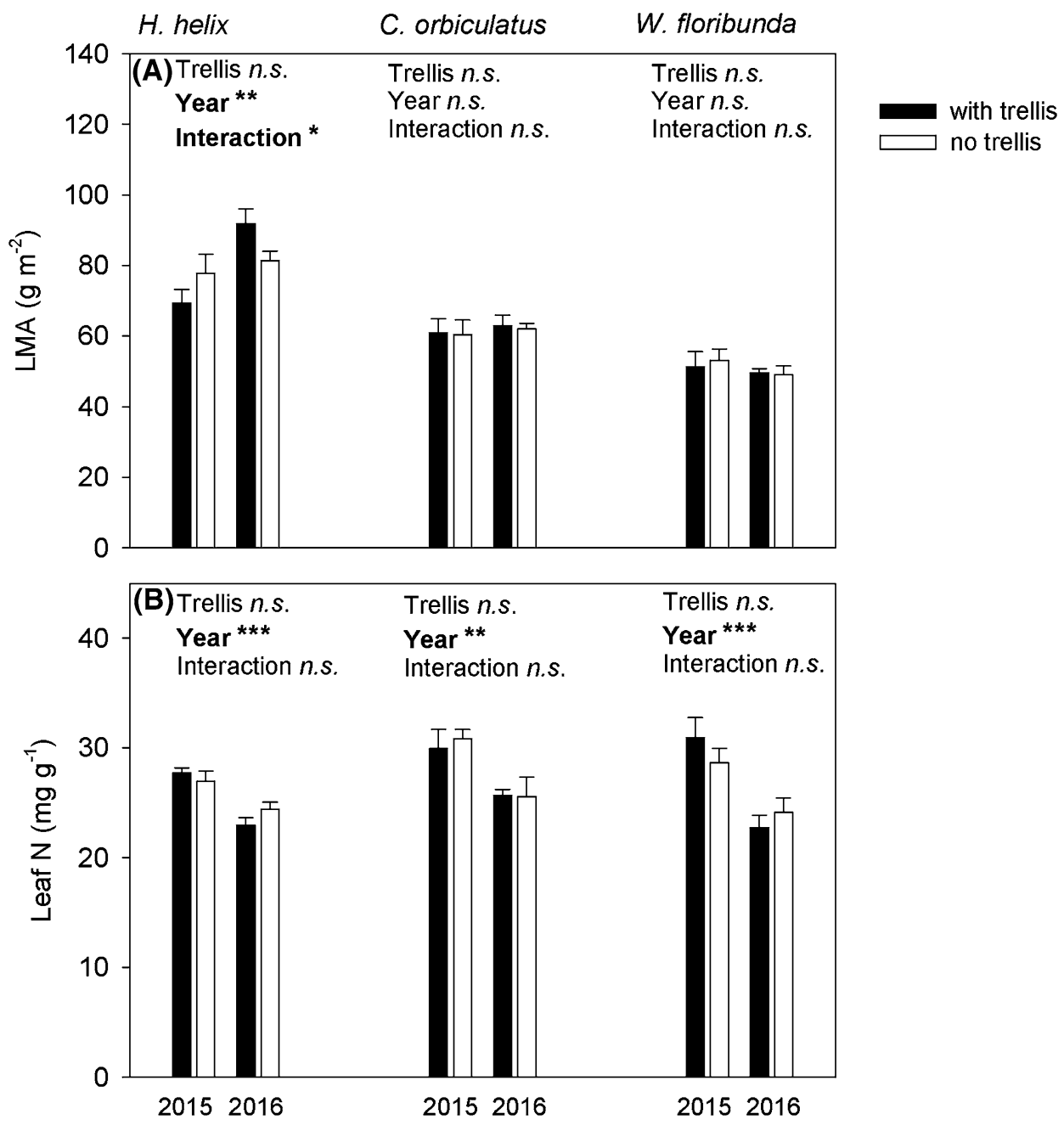

for whole plants (Tsugawa et al. 1992; den Dubbelden and Oosterbeck 1995) or for aboveground parts (Gartner 1991b; Tsugawa et al. 1992; Gianoli 2002). In an experiment manipulating intraspecific density of a herbaceous climber Gallium aparine, the presence of support stimulated growth only under the highest plant density suggesting an effective shade escape (Puntieri and Pyšek 1993). Finally, and surprisingly, the root climber $H$. helix grew more strongly without, than with support. Could this result be explained by the exclusively prostrate stems of unsupported plants producing more adventitious absorptive roots than the relatively less numerous prostrate shoots of supported plants? By efficiently penetrating soil outside of the barrels such roots would improve plant access to soil nutrients. Our data offer only a hint of support for this hypothesis, since the root systems of unsupported $H$. helix plants had somewhat, although insignificantly, larger average ARMF in comparison with supported plants. This explanation is certainly consistent with the higher plant $\mathrm{N}$ pool of unsupported plants showing that unsupported $H$. helix were more efficient at acquiring and/or conserving N. H. helix represents a class of climbers that colonize forest floor by vegetative spread of rooting shoots, but expand into canopy for sexual reproduction (Metcalfe 2005). At least in such lianas climbing growth, in contrast to horizontal spreading, may restrict access to soil resources and lead to disadvantage in vegetative growth. Such result does not seem to have been reported before. It is certainly worthy of further exploration as it indicates a cost associated with climbing that, in understory situations, must be weighed against benefits of improved access to light. The above results, together with earlier literature reports, thus show that, in the absence of light and space limitation, growth responses to trellis availability vary strongly among climber species.

Fast biomass accumulation is usually associated with large distribution ratio of biomass and/or $\mathrm{N}$ to leaves (Evans 1972; Poorter 1989). The results for $W$. floribunda, in which trellis use resulted in increased plant biomass, LMF and LNF, were consistent with this general rule. Notably, the enhancement of LNF was relatively greater than for LMF (because of the higher leaf- than whole-plant $\mathrm{N}$ concentration; not shown), suggesting a proportionally higher 
allocation of $\mathrm{N}$ to photosynthesis. In contrast, in $\mathrm{H}$. helix plant biomass was greater in unsupported than in supported plants even though trellis use did not alter the relative resource distribution. It is conceivable that vertical shoot orientation in $H$. helix (and possibly, other species) resulted in a decreased photosynthetic rate as a result of increased resistance to water transport or departure from optimal leaf temperature, leading to lower biomass gain even when leaves constituted similar plant mass fraction as in unsupported plants. This brings into focus the various more or less subtle micro-environmental factors, other than irradiance, that are inevitably altered as liana expands from the understory into the canopy, such as tissue temperature, relative humidity of adjacent atmosphere or exposure to wind. Not all these changes are favorable for photosynthesis, hence the expansion into canopy may yield additional costs in terms of lower biomass accumulation that need to be considered as an aspect of liana ecological strategy. This may be especially true in the temperate zone where climbing liana stems are especially vulnerable to frost-induced hydraulic damage (Castillo and Lusk 2013).

Stimulation of liana growth by trellis availability may be mediated not necessarily by an improvement in plant energy capture but, assuming lack of strong limitation by photosynthate availability, it may also be regulated as a response to environmental signal. Firstly, climbing plants may actively search for support and this searching growth may require morphological modifications of the shoot system. In $C$. orbiculatus and $W$. floribunda searching occurs via self-supporting shoots performing nutational movements. At least in W. floribunda, the apical portion of the shoot may die back after failing to encounter support (Wyka pers. observation). It has been proposed that at least some lianas perceive the presence of trellis and approach it by directional shoot growth (e.g., through skototropism; Strong and Ray 1975; Price and Wilcut 2007). However, it is not known how widespread the ability for active trellis localization is in different liana species or climbing types nor what are the underlying signal perception mechanisms. Secondly, it seems that the contact with support in W. floribunda encouraged stem extension as suggested by greater total stem length in supported, in comparison with similarly sized unsupported, plants. Notably, this response occurred in high-light environment and was possibly mediated by a thigmomorphogenetic or gravitropic mechanism. Stimulation of stem extension in supported shoots has been reported previously for this (Sakai and Suzuki 1999) and other species (Putz 1984; Gartner 1991b; den Dubbelden and Oosterbeek 1995; Gianoli 2002), although in those reports measurements were not adjusted for plant size. Finally, climbers as a group show a strong capability to modify morphology, growth habit and ecological strategy in relation to light availability and to the spectral shade signals (Puntieri and Pyšek 1993; Gianoli
2002; Leicht and Silander 2006; Cai et al. 2008). It is likely that under shading the stimulatory effect of trellis on shoot growth and the plastic modifications of biomass distribution in $W$. floribunda would have been yet quantitatively greater (as found for Ipomoea by Gianoli 2002), and could occur also in $C$. orbiculatus, another light demanding species. This is because shading itself may act as an environmental signal inducing the search for support and leading to increased investment in stem extension in those canopy lianas that do not have a lasting self-supporting phase (Chen et al. 2014). This leads to an interesting question, to what extent such shade avoidance operates in lianas with a clear shade-adapted juvenile phase, such as H. helix. The alternative between shade avoidance and shade tolerance in lianas and the role of trellis availability in triggering the different types of growth merits further investigation.

Similarly to many climbers, the three species studied here are naturally clonal to various degrees. Both $H$. helix and $W$. floribunda produce dimorphic long shoots, i.e., orthotropic climbing shoots and plagiotropic creeping shoots (stolons in the latter species) and C. orbiculatus produces belowground shoots that exhibit plagiotropic growth and explore the area eventually establishing clonal populations (Sakai et al. 2002; Williams and Timmins 2003; Metcalfe 2005; Mori et al. 2018). In this study, plagiotropic shoots were produced by all species but belowground shoots described elsewhere were not observed in $C$. orbiculatus. Plagiotropic shoots of $H$. helix produced dense leafy mats covering the ground around the barrels while those of W. floribunda and C. orbiculatus extended away and were mostly unbranched. In many liana species horizontal clonal growth is at least a temporary alternative to climbing growth, enhancing the ability of the plant to harvest soil resources and to eventually locate a suitable support. Rather spectacular plastic changes of leaf and stem morphology accompanying switches between climbing and ground-dwelling modes have been described for climbers in the tropical Araceae (Ray 1992) but were not found in this study, perhaps because of the apparent uniformity of light environment between the two growth modes. It is not known to what extent the propensity for clonal growth is directly controlled by unavailability of support, but it certainly may constitute a viable foraging strategy in response to local absence of trellis, by analogy with foraging strategies of many clonal plants that plastically modify their growth form in search for heterogeneously distributed resources (de Kroon and Hutchings 1995).

The evolutionary advantage of lianas over self-supporting forms arises from an increased allocation of biomass to leaves achieved due to lower requirement for other organs: stems (Darwin 1865; Wyka et al. 2013) or roots (Wyka et al. unpublished). We hypothesized that in the absence of support, biomass allocation pattern in lianas may shift toward that typical for self-supporting plants, recapitulating 
to some extent the evolutionary divergence between growth forms. The expected increase of LMF in response to trellis was found in $W$. floribunda, occurring simultaneously with a decrease in RMF but also an increase in SMF (see also Sakai and Suzuki 1999). Although reduced stem biomass requirement is frequently invoked as an intrinsic feature of lianas, liana stems, although thinner, tend to be much longer than stems of self-supporting species, hence the SMF of lianescent forms may remain high (Gartner 1991b; Kaneko and Homma 2006). Thus overall, the plastic changes in biomass distribution in W. floribunda induced by trellis climbing indeed appear to recapitulate changes that accompanied evolution of climbers from self-supporting forms. In contrast, biomass distribution was a conservative trait in $H$. helix, a root-climbing species in which roots constitute very small $(<20 \%)$ fraction of plant biomass, and stems, at least in the earliest years of life, tend to be densely foliated both while creeping on the ground and clinging to tree trunk surface. Since root attachment to tree bark in this species is strong and durable, its stems probably face less stringent mechanical demand than in the twinning climbers, being involved mostly in transport and storage. All this suggests that a switch from creeping to climbing may require only a limited adjustment of allocation pattern, at least within the age span and trellis height studied here.

In summary, the three lianas included in the study responded to trellis availability in species-specific manners. Trellis use enhanced stem extension beyond what was expected from allometric relationship of stem length and plant biomass in W. floribunda but not in the other two species. Likewise, climbing a trellis resulted in an increased biomass accumulation in $W$. floribunda, had no effect in C. orbiculatus but caused lower biomass accumulation in H. helix. The growth response to trellis in W. floribunda could be attributed to a greater relative biomass distribution to leaves, which occurred at the expense of distribution to roots. The lack of stimulation of stem extension or growth noted in climbing $C$. orbiculatus was consistent with the lack of change in biomass distribution in this species. In contrast, inhibition of biomass accumulation in trellis-grown H. helix was not accompanied by altered biomass distribution, but was likely related to less efficient harvesting of soil resources, suggesting a trade-off associated with switching from prostrate to climbing habit in shade-adapted, clonal lianas. These results highlight the plasticity of plant habit, growth rate and allocation pattern triggered by trellis as a potentially important adaptive mechanism in at least some liana species, and point to the potential physiological costs of climbing.

Author contribution statement TPW, JO and MZ conceived and designed the study; KN and TPW conducted the experiment; TPW, MBZ and JM organized harvest and biomass processing; RŻ conducted laboratory analyses; TPW analyzed the data and wrote the manuscript with subsequent input from all coauthors.

Acknowledgements This work was supported by the National Science Center Poland (Grant 2011/03/B/NZ8/02190 to T.P.W.).

Open Access This article is distributed under the terms of the Creative Commons Attribution 4.0 International License (http://creativeco mmons.org/licenses/by/4.0/), which permits unrestricted use, distribution, and reproduction in any medium, provided you give appropriate credit to the original author(s) and the source, provide a link to the Creative Commons license, and indicate if changes were made.

\section{References}

Ackerly DD (1992) Light, leaf age, and leaf nitrogen concentration in a tropical vine. Oecologia 89:596-600. https://doi.org/10.1007/ BF00317169

Angyalossy V, Angeles G, Pace MR, Lima AC, Dias-Leme CL, Lohmann LG, Madero-Vega C (2012) An overview of the anatomy, development and evolution of the vascular system of lianas. Plant Ecol Divers 5:167-182. https://doi.org/10.1080/17550 874.2011.615574

Cai Z-Q, Poorter L, Han Q, Bongers F (2008) Effects of light and nutrients on seedlings of tropical Bauhinia lianas and trees. Tree Physiol 28:1277-1285. https://doi.org/10.1093/treephys/28.8.1277

Castillo M-J, Lusk CH (2013) Vascular performance of woody plants in a temperate rain forest: lianas suffer higher levels of freeze-thaw embolism than associated trees. Funct Ecol 27:403-412. https:// doi.org/10.1111/1365-2435.12045

Chen Y-J, Bongers F, Zhang J-L, Liu J-Y, Cao K-F (2014) Different biomechanical design and ecophysiological strategies in juveniles of two liana species with contrasting growth habit. Am J Bot 101:925-934. https://doi.org/10.3732/ajb.1300429

Darwin CR (1865) On the movements and habits of climbing plants. Bot J Linn Soc 9:1-118

de Kroon H, Hutchings MJ (1995) Morphological plasticity in clonal plants: the foraging concept reconsidered. J Ecol 83:143-152. https://doi.org/10.2307/2261158

den Dubbelden KC, Oosterbeek B (1995) The availability of external support affects allocation patterns and morphology of herbaceous climbing plants. Funct Ecol 9:628-634. https://doi. org/10.2307/2390154

Evans GC (1972) The quantitative analysis of plant growth. University of California Press, Berkeley

Frey D, Frick H (1987) Altered partitioning of new dry matter in Hedera helix L. (Araliaceae) induced by altered orientation. Bull Torrey Bot Club 114:407-411. https://doi.org/10.2307/2995996

Gallenmüller F, Rowe N, Speck T (2004) Development and growth form of the neotropical liana Croton nuntians: the effect of light and mode of attachment on the biomechanics of the stem. J Plant Growth Regul 23:83-97. https://doi.org/10.1007/s0034 4-004-0045-z

Gartner BL (1991a) Is the climbing habit of poison oak ecotypic? Funct Ecol 5:696-704. https://doi.org/10.2307/2389490

Gartner BL (1991b) Relative growth rates of vines and shrubs of western poison oak, Toxicodendron diversilobum (Anacardiaceae). Am J Bot 78:1345-1353. https://doi.org/10.2307/2445273 
Gartner BL (1991c) Structural stability and architecture of vines vs., shrubs of poison oak, Toxicodendron diversilobum. Ecology 72:2005-2015. https://doi.org/10.2307/1941555

Gentry AH (1991) The distribution and evolution of climbing plants. In: Putz FE, Mooney HA (eds) The biology of vines. Cambridge University Press, Cambridge, pp 3-50

Gianoli E (2002) Phenotypic responses of the twining vine Ipomoea purpurea (Convolvulaceae) to physical support availability in sun and shade. Plant Ecol 165:21-26. https://doi.org/10.1023/A:10214 12030897

Gianoli E, Molina-Montenegro MA (2005) Leaf damage induces twining in a climbing plant. N Phytol 167:385-390. https://doi.org/1 0.1111/j.1469-8137.2005.01484.x

Isnard S, Silk WK (2009) Moving with climbing plants from Charles Darwin's time into the 21st century. Am J Bot 96:1205-1221. https://doi.org/10.3732/ajb.0900045

Kaneko Y, Homma K (2006) Differences in the allocation patterns between liana and shrub Hydrangea species. Plant Spec Biol 21:147-153. https://doi.org/10.1111/j.1442-1984.2006.00160.x

Larson KC (2000) Circumnutation behavior of an exotic honeysuckle vine and its native congener: influence on clonal mobility. Am J Bot 87:533-538. https://doi.org/10.2307/2656597

Leicht SA, Silander JA Jr (2006) Differential responses of invasive Celastrus orbiculatus (Celastraceae) and native C. scandens to changes in light quality. Am J Bot 93:972-977. https://doi. org/10.3732/ajb.93.7.972

Metcalfe DJ (2005) Hedera helix L. J Ecol 93:632-648. https://doi.org /10.1111/j.1365-2745.2005.01021.x

Mori H, Ueno S, Matsumoto A, Kamijo T, Tsumura Y, Masaki T (2018) Large contribution of clonal reproduction to the distribution of deciduous liana species (Wisteria floribunda) in an oldgrowth cool temperate forest: evidence from genetic analysis. Ann Bot 121:359-365. https://doi.org/10.1093/aob/mcx153

Nabe-Nielsen J (2004) Demography of Machaerium cuspidatum, a shade-tolerant neotropical liana. J Trop Ecol 20:505-516. https ://doi.org/10.1017/S0266467404001609

Poorter H (1989) Interspecific variation in relative growth rate: on ecological causes and physiological consequences. In: Lambers $\mathrm{H}$, Cambridge ML, Konings H, Pons TL (eds) Causes and consequences of variation in growth rate and productivity of higher plants. SPB Academic Publishing, The Hague, pp 45-68

Poorter H. Sack L (2012) Pitfalls and possibilities in the analysis of biomass allocation patterns in plants. Front Plant Sci 3:259. https ://doi.org/10.3389/fpls.2012.00259

Poorter H, Niinemets Ü, Poorter L, Wright IJ, Villar R (2009) Causes and consequences of variation in leaf mass per area (LMA): a meta-analysis. N Phytol 182:565-588. https://doi.org/10.111 1/j.1469-8137.2009.02830.x

Poorter H, Jagodziński AM, Ruiz-Peinado R, Kuyah S, Luo Y, Oleksyn J, Usoltsev VA, Buckley TN, Reich PB, Sack L (2015) How does biomass distribution change with size and differ among species? An analysis for 1200 plant species from five continents. N Phytol 208:736-749. https://doi.org/10.1111/nph.13571

Price AJ, Wilcut JW (2007) Response of ivy leaf morning glory (Ipomoea hederacea) to neighboring plants and objects. Weed Technol 21:922-927. https://doi.org/10.1614/WT-06-146.1

Puntieri JG, Pyšek P (1993) The effects of physical support and density on biomass production and size hierarchies of Galium aparine populations. Oikos 67:279-284. https://doi.org/10.2307/3545472

Putz FE (1984) The natural history of lianas on Barro Colorado Island, Panama. Ecology 65:1713-1724. https://doi.org/10.2307/1937767

Ray TS (1992) Foraging behavior in tropical herbaceous climbers (Araceae). J Ecol 80:189-203. https://doi.org/10.2307/2261006

Rowe NP, Speck T (2005) Plant growth forms: an ecological and evolutionary perspective. N Phytol 166:61-72. https://doi.org/10.11 11/j.1469-8137.2004.01309.x

Sakai A, Suzuki W (1999) Effect of support on the growth of a woody vine, Wisteria floribunda DC. (Leguminosae). J For Res Jpn 4:183-186

Sakai A, Nomiya H, Suzuki W (2002) Horizontal distribution of stolons of a temperate liana Wisteria floribunda DC. and its ecological significance. J For Res Jpn 7:125-130. https://doi.org/10.1007/ BF02762600

Strong DR, Ray TS (1975) Host tree location behavior of a tropical vine (Monstera gigantea) by skototropism. Science 190:804-806. https ://doi.org/10.1126/science.190.4216.804

Tsugawa H, Shimizu T, Sasek TW, Nishikawa K (1992) The climbing strategy of kudzu-vine (Pueraria lobata Ohwi): 1: comparisons of branching behaviour, and dry matter and leaf area production between staked and no stake kudzu plants. Sci Rep Fac Agric Kobe Univ 20:1-6

Valladares F, Gianoli E, Saldaña A (2011) Climbing plants in a temperate rainforest understorey: searching for high light or coping with deep shade? Ann Bot 108:231-239. https://doi.org/10.1093/ aob/mcr132

Williams PA, Timmins SM (2003) Climbing spindle berry (Celastrus orbiculatus Thunb.) biology, ecology, and impacts in New Zealand. Science for conservation, vol 234. Department of Conservation, Wellington

Wyka TP, Oleksyn J, Karolewski P, Schnitzer SA (2013) Phenotypic correlates of the lianescent growth form: a review. Ann Bot 112:1668-1681. https://doi.org/10.1093/aob/mct236

Publisher's Note Springer Nature remains neutral with regard to jurisdictional claims in published maps and institutional affiliations. 